\section{Como as crianças hiperléxicas aprendem a ler? Um estudo de uma criança autista}

\section{How do hyperlexic children learn to read? A study of an autistic child}

Sr. Editor,

A hiperlexia é uma desordem da leitura caracterizada por uma habilidade avançada de leitura de palavras (decodificação) a despeito de dificuldades pronunciadas de compreensão da linguagem. Com freqüência, vem associada às desordens do espectro autista. ${ }^{1,2}$

Grande parte do que conhecemos sobre a hiperlexia advém de avaliações de adolescentes ou crianças em idade escolar. Isso é lamentável, uma vez que o início precoce e espontâneo da habilidade de decodificação é uma característica importante da hiperlexia. No presente relato, descrevemos os resultados da avaliação de um menino hiperléxico de três anos e nove meses de idade, que participou de um estudo no laboratório de Psicologia do Desenvolvimento Cognitivo e da Linguagem da Universidade Federal de Minas Gerais (UFMG) sobre a habilidade de leitura nos transtornos do espectro autista (Comitê de Ética da UFMG; Protocolo: 530/04). Por ocasião da avaliação, a criança apresentava vários comportamentos típicos do transtorno autista, de acordo com os critérios da CID-10. ${ }^{3}$ O diagnóstico de autismo foi realizado por dois profissionais: um psiquiatra e uma psicóloga.

Além de testes de conhecimento das letras e de leitura, a criança foi submetida a testes de compreensão da linguagem e a várias medidas de processamento fonológico (ver Tabela 1). Uma vez que várias dessas medidas são experimentais, seu desempenho foi comparado ao desempenho de um grupo de crianças típicas (idade média $=6$ anos) com a mesma habilidade de leitura de palavras. O grupo controle foi recrutado entre crianças matriculadas em classes da pré-escola de uma escola particular na cidade de Belo Horizonte. Segundo as professoras, nenhuma apresentava sinais de distúrbios do desenvolvimento. Conforme ilustrado na Tabela 1 , embora a criança hiperléxica tenha apresentado um desempenho semelhante ao dos controles no teste de leitura de palavras, seu desempenho nos testes de compreensão da linguagem (oral e escrita) foi muito inferior.

Tabela 1 - Escores brutos nas várias medidas em função do diagnóstico

\begin{tabular}{|c|c|c|c|}
\hline \multirow[t]{2}{*}{ Medidas } & \multirow{2}{*}{$\begin{array}{l}\text { Hiperléxico } \\
(n=1)\end{array}$} & \multicolumn{2}{|c|}{$\begin{array}{l}\text { Crianças tipicas } \\
\qquad(n=8)\end{array}$} \\
\hline & & Média & Amplitude \\
\hline \multicolumn{4}{|l|}{ Compreensão da linguagem } \\
\hline Vocabulário oral (escore max. $=204$ ) & 11 & 88,38 & $75-103$ \\
\hline Vocabulário escrito (escore max. $=204$ ) & 4 & 76,50 & $60-97$ \\
\hline \multicolumn{4}{|l|}{ Leitura } \\
\hline Leitura de palavras (escore $\max .=70$ ) & 41 & 42,63 & $40-46$ \\
\hline $\begin{array}{l}\text { Leitura de pseudopalavras (escore } \\
\max .=20 \text { ) }\end{array}$ & 17 & 15,38 & $14-18$ \\
\hline \multicolumn{4}{|l|}{ Conhecimento das letras } \\
\hline Nomes das letras (escore max. $=24$ ) & 23 & 23,13 & $22-24$ \\
\hline Sons das letras (escore max. $=23$ ) & 11 & 20,38 & $18-22$ \\
\hline \multicolumn{4}{|l|}{ Processamento Fonológico } \\
\hline CF (escore max. $=12$ ) & 0 & 10,88 & $8-12$ \\
\hline MF (escore max. = 9) & 5 & 4,88 & 4-5 \\
\hline NSR de digitos (tempo em segs.) & 52 & 44,13 & $36-57$ \\
\hline NSR de letras (tempo em segs.) & 45 & 45,25 & $37-60$ \\
\hline
\end{tabular}

Nota: $C F$ = consciência fonológica; $M F=$ Memória fonológica de curto-prazo; NSR nomeação seriada rápida. Uma descrição detalhada das medidas listadas na tabela poderá ser obtida através de solicitação aos autores.
Os resultados de estudos com crianças em idade escolar sugerem que os hiperléxicos aprendem a ler palavras como as crianças típicas, i.e., através do processamento e do armazenamento das relações letra-som nas palavras. ${ }^{1,2,4}$ A julgar pelos nossos resultados, isso também é verdade para crianças em idade préescolar. Com efeito, não encontramos diferenças entre a criança hiperléxica e as demais crianças na leitura de pseudopalavras, nem tampouco em duas das medidas de processamento fonológico: a memória fonológica e a nomeação seriada rápida. É possível, no entanto, que o processamento das relações entre as letras e os sons ocorra implicitamente na hiperlexia.

Como pode ser visto na Tabela 1 , ao contrário das demais medidas de processamento fonológico, a criança hiperléxica não conseguiu realizar uma tarefa simples de consciência fonológica que, contudo, pressupõe a habilidade de prestar atenção consciente aos sons da fala. Além disso, apresentou um desempenho muito inferior ao das crianças típicas na medida de conhecimento dos sons das letras. Uma vez que o seu desempenho foi praticamente perfeito em uma tarefa semelhante que avaliava o conhecimento do nome das letras, é pouco provável que o seu fracasso naquela medida possa ser explicado em termos de uma dificuldade de compreensão. Ao invés disso, esses resultados sugerem a hipótese de que as crianças hiperléxicas aprendem a conectar a escrita e a fala implicitamente, i.e., sem atenção consciente às relações letra-som nas palavras.

É possível que a chave para a habilidade de decodificação excepcionalmente boa e precoce de crianças hiperléxicas seja precisamente a sua indiferença à linguagem como um instrumento de comunicação. Ao contrário de crianças típicas, que precisam aprender a desconsiderar o significado da linguagem para aprender a ler, as crianças hiperléxicas apenas gradualmente aprendem as funções comunicativas da linguagem. Como resultado, é possível que usem as suas habilidades fonológicas para computar relações letra-som nas palavras. Tal como bebês de oito meses aprendem a isolar palavras com base na detecção de seqüências recorrentes de sons na corrente da fala, ${ }^{5}$ é possível que as crianças hiperléxicas baseiem-se em processos de aprendizagem estatística para computar tais relações.

\section{Agradecimentos}

Agradecemos às crianças que participaram do estudo. Somos também gratas ao Conselho Nacional de Ciência e Tecnologia (CNPq), pelo apoio ao nosso trabalho.

\author{
Cláudia Cardoso-Martins \\ Departamento de Psicologia, \\ Universidade Federal de Minas Gerais (UFMG), \\ Belo Horizonte (MG), Brasil \\ Juliane Ribeiro da Silva \\ Prefeitura Municipal de Belo Horizonte, \\ Belo Horizonte (MG), Brasil
}

\section{References}

1. Grigorenko EL, Klin A, Volkmar F. Annotation: Hyperlexia: disability or superability? J Child Psychol Psychiatry. 2003;44(8):1079-91.

2. Newman TM, Macomber D, Babitz T, Volkmar F, Grigorenko EL. Hyperlexia in children with autism spectrum disorders. J Autism Dev Disord. 2007;37(4):760-74.

3. Organização Mundial de Saúde. Classificação dos Transtornos Mentais e de Comportamento da CID 10: Descrições Clínicas e Diretrizes Diagnósticas. Porto Alegre: Artes Médicas; 1993.

4. Welsh MC, Pennington BF, Rogers $S$. Word recognition and comprehension skills in hyperlexic children. Brain Lang. 1987;32(1):76-96.

5. Saffran JR, Aslin RN, Newport EL. Statistical learning by 8-month old infants. Science. 1996;274(5294):1926-8. 
Financiamento e conflito de interesses

\begin{tabular}{|c|c|c|c|c|c|c|c|}
\hline $\begin{array}{l}\text { Membro do grupo } \\
\text { de autores }\end{array}$ & $\begin{array}{l}\text { Local de } \\
\text { trabalho }\end{array}$ & $\begin{array}{l}\text { Verba de } \\
\text { pesquisa }\end{array}$ & $\begin{array}{l}\text { Outro apoio à pesquisa ou } \\
\text { educação médica continuada }\end{array}$ & $\begin{array}{c}\text { Honorários de } \\
\text { palestrante }\end{array}$ & $\begin{array}{l}\text { Participação } \\
\text { acionária }\end{array}$ & $\begin{array}{c}\text { Consultorl Conselho } \\
\text { consultivo }\end{array}$ & Outro $^{3}$ \\
\hline $\begin{array}{l}\text { Cláudia Cardoso- } \\
\text { Martins }\end{array}$ & UFMG & - & - & - & - & - & - \\
\hline $\begin{array}{l}\text { Juliane Ribeiro da } \\
\text { Silva }\end{array}$ & $\begin{array}{c}\text { Prefeitura } \\
\text { Municipal de } \\
\text { Belo } \\
\text { Horizonte }\end{array}$ & - & - & - & - & - & - \\
\hline
\end{tabular}

* Modesto

** Significativa

*** Significativa. Montantes fornecidos à instituição do autor ou a colega para pesquisa onde o autor tem participação, não diretamente ao autor.

Nota: UFMG = Universidade Federal de Minas Gerais.

Para mais informaçōes, consultar Instruçōes aos autores. 